\title{
An Integrated Method for Designing Airfoils Shapes
}

\author{
Wang Xudong, ${ }^{1,2}$ Wang Licun, ${ }^{1,2}$ and Xia Hongjun' \\ ${ }^{1}$ Chongqing Key Laboratory of Manufacturing Equipment Mechanism Design and Control, \\ Chongqing Technology and Business University, Chongqing 400067, China \\ ${ }^{2}$ Research Center of System Health Maintenance, Chongqing Technology and Business University, Chongqing 400067, China
}

Correspondence should be addressed to Wang Xudong; wangxudong916@163.com

Received 31 July 2015; Accepted 22 October 2015

Academic Editor: Mustafa Tutar

Copyright (C) 2015 Wang Xudong et al. This is an open access article distributed under the Creative Commons Attribution License, which permits unrestricted use, distribution, and reproduction in any medium, provided the original work is properly cited.

\begin{abstract}
A new method for designing wind turbine airfoils is presented in this paper. As a main component in the design method, airfoil profiles are expressed in a trigonometric series form using conformal transformations and series of polynomial equations. The characteristics of the coefficient parameters in the trigonometric expression for airfoils profiles are first studied. As a direct consequence, three generic airfoil profiles are obtained from the expression. To validate and show the generality of the trigonometric expression, the profiles of the NACA 64418 and S809 airfoils are expressed by the present expression. Using the trigonometric expression for airfoil profiles, a so-called integrated design method is developed for designing wind turbine airfoils. As airfoil shapes are expressed with analytical functions, the airfoil surface can be kept smooth in a high degree. In the optimization step, drag and lift force coefficients are calculated using the XFOIL code. Three new airfoils CQ-A15, CQ-A18, and CQ-A21 with a thickness of $15 \%, 18 \%$, and $21 \%$, respectively, are designed with the new integrated design method.
\end{abstract}

\section{Introduction}

Design of airfoils for wind turbine blades is a very basic and important task for designing wind turbine rotors [1]. From the seventies of last century, NASA began on working with airfoil design using a code developed by Eppler and Somers $[2,3]$. The philosophy of the design method is that a lift-drag polar was first defined according to the requirements of a designed airfoil and then a pressure coefficient distribution along the airfoil was deduced. Based on the pressure distribution, a potential velocity distribution was obtained. Using the conformal mapping method and the prescribed velocity distribution, the shape of the candidate airfoil was designed. Compared with other inverse methods, the conformal mapping method was used in the Eppler code and it allowed the velocity distribution to be specified along the airfoil surface at different angles of attack [4-8].

In the past 20 years various airfoils have been designed especially for wind turbines. The first examples are the NREL nine airfoil families from the National Renewable Energy Laboratory (NREL) $[9,10]$ that were designed in 1995 for various rotors of horizontal-axis wind turbines (HAWTs) using the Eppler Airfoil Design and Analysis Code. Generally, the new airfoil families were designed such that the maximum lift coefficient is relatively insensitive to wall roughness. These airfoil families have been successfully used in stall-regulated, variable-pitch, and variable-rpm wind turbines. The second example is the DU airfoils that were designed at DUT (Delft University of Technology) and tested in the DUT wind tunnel [11]. The DU airfoils are referred to as DU yy-W-xxx, in which DU stands for Delft University; yy is the year in which the airfoil was designed; $\mathrm{W}$ denotes the wind energy application and the last three digits give 10 times the airfoil maximum thickness in percent of the chord. The third example is the RIS $\varnothing$ airfoils from RIS $\varnothing$ National Laboratory in Denmark. The development of these airfoils started in the mid-1990s and until now three airfoil families have been developed, RIS $\varnothing-A 1, R I S \varnothing-P$, and RIS $\varnothing-B 1$ [12]. Another type of wind turbine airfoils is the FFA airfoils from the Aeronautical Research Institute of Sweden [13].

In this paper, a new airfoil design method is described. Based on the common characteristics of the existing airfoils, 
a general expression for airfoils is developed. The airfoil shape is controlled by the coefficients in the series. The airfoil performance is calculated by using the XFOIL code [14]. The accuracy of XFOIL for airfoil flow predictions was investigated in [15]. Since the code is based on solving the viscous integral boundary layer equation and the inviscid Euler equation, it can be run fast on a computer and therefore it is a favorable solver to be used in the design model. As the airfoil equation is directly related to the lift and the drag of the airfoil, it is easier to design any expected airfoils. Compared to the traditional inverse design method, the new design method is more direct and accurate.

\section{Integrated Design Method for Airfoil Profiles}

2.1. Trigonometric Expression of Airfoil Profiles. From the earlier Joukowsky transformation investigations on airfoils (e.g., $[16,17])$, it is known that any airfoil profile can be expressed with a conformal mapping and an analytical function of a finite series of Fourier expansions. Following this idea, the shape expression of an airfoil will be constructed similarly by using a conformal mapping and a Taylor series.

In general, any airfoil profile can be mapped to a near circle by the relation

$$
z=z^{\prime}+\frac{a^{2}}{z^{\prime}}
$$

where $a=c / 4, c$ is airfoil chord, $z$ is the complex variable in the airfoil plane, and $z^{\prime}$ is the one in the near circle plane. The coordinates of $z$ are defined as

$$
z=x+i y .
$$

Using polar coordinates $(r, \theta)$ in the near circle plane, the coordinates of the airfoil can be expressed as

$$
\begin{aligned}
& x=\left(r+\frac{a^{2}}{r}\right) \cos \theta, \\
& y=\left(r-\frac{a^{2}}{r}\right) \sin \theta .
\end{aligned}
$$

On the other hand, the coordinates of $z^{\prime}$ in the near circle plane can also be expressed as

$$
z^{\prime}=r \exp (\varphi+i \theta)
$$

where the real part of the exponential argument $\varphi$ is a function of $\theta$ as $\varphi=\varphi(\theta)$. The function $\varphi(\theta)$ is expressed in a series of sine and cosine functions as

$$
\begin{aligned}
\varphi(\theta)= & a_{1}(1-\cos \theta)+b_{1} \sin \theta+a_{2}(1-\cos \theta)^{2} \\
& +b_{2} \sin ^{2} \theta+\cdots+a_{k}(1-\cos \theta)^{k}+b_{k} \sin ^{k} \theta \\
& +\cdots \quad k=1,2,3, \ldots, n,
\end{aligned}
$$

where $a_{1}, b_{1}, a_{2}, b_{2}, \ldots, a_{k}, b_{k}$ are the unknown coefficients which are determining the airfoil shape. From (5), it is noticed

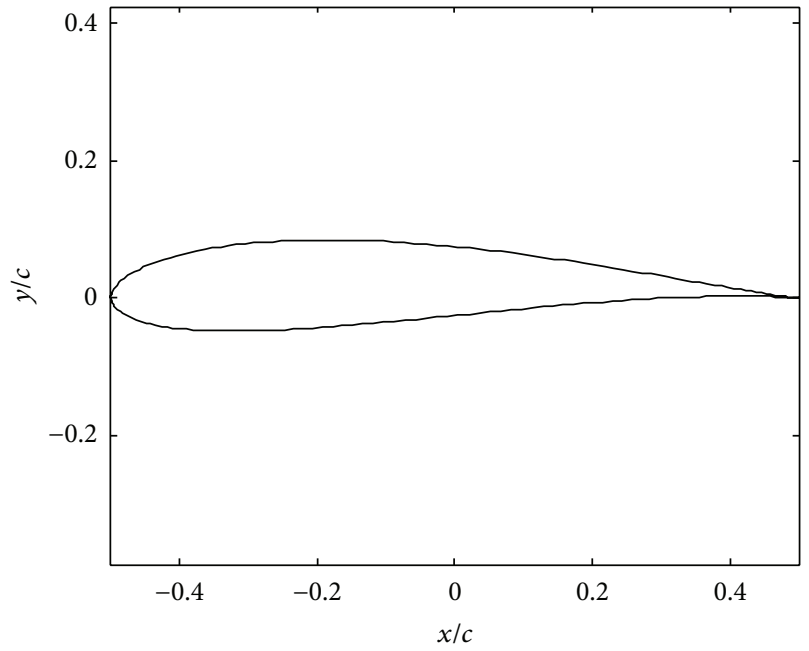

FIGURE 1: First type of airfoil profiles.

that $\varphi(0)=0$. This point corresponds to the sharp trailing edge of the airfoil. The shape of the airfoil is determined combining (1) and (5).

2.2. Characteristics of the Trigonometric Expression. In order to analyse the characteristics of an airfoil desired by using the introduced expression, three special cases will be considered in this section. These cases correspond to three types of airfoils. For convenience, the airfoil coordinates are normalized by the airfoil chord.

Case 1. Letting the first two coefficients be $a_{1}=0.1$ and $b_{1}=$ 0.05 , putting all other coefficients equal to 0 , the function $\varphi(\theta)$ becomes

$$
\varphi(\theta)=0.1 \times(1-\cos \theta)+0.05 \times \sin \theta .
$$

From (1), (4), and (6), an airfoil shape is obtained as shown in Figure 1.

Case 2. Letting the third and fourth coefficients be $a_{2}=0.05$ and $b_{2}=0.05$, respectively, setting all other coefficients equal to 0 , the function $\varphi(\theta)$ becomes

$$
\varphi(\theta)=0.05 \times(1-\cos \theta)^{2}+0.05 \times \sin ^{2} \theta .
$$

From (1), (4), and (7), a second airfoil shape is obtained as shown in Figure 2.

Case 3. Letting the fifth and sixth coefficients be $a_{3}=0.03$ and $b_{3}=0.05$, respectively, setting all other coefficients equal to 0 , the function $\varphi(\theta)$ becomes

$$
\varphi(\theta)=0.03 \times(1-\cos \theta)^{3}+0.05 \times \sin ^{3} \theta
$$

From (1), (4), and (8), the shape of this airfoil shape is obtained as shown in Figure 3. 


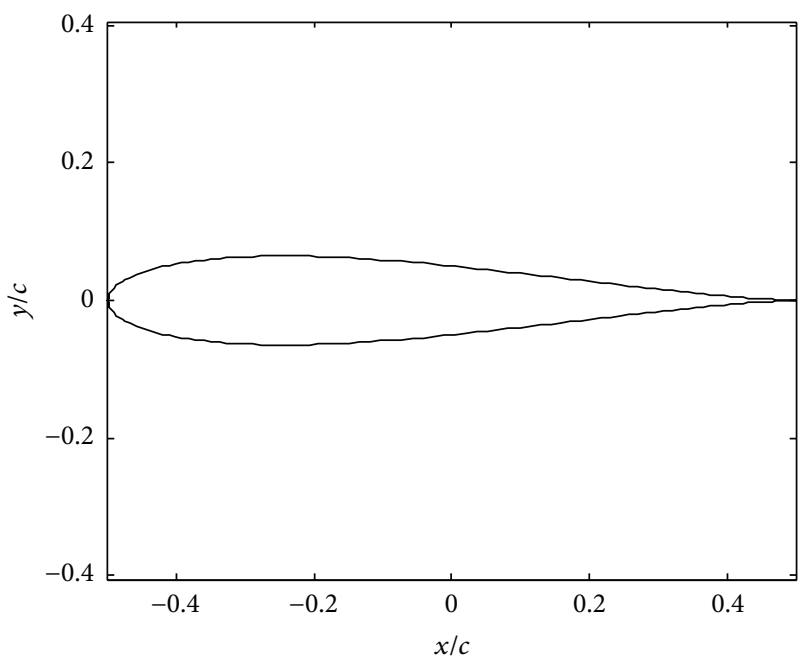

FIGURE 2: Second type of airfoil profiles.

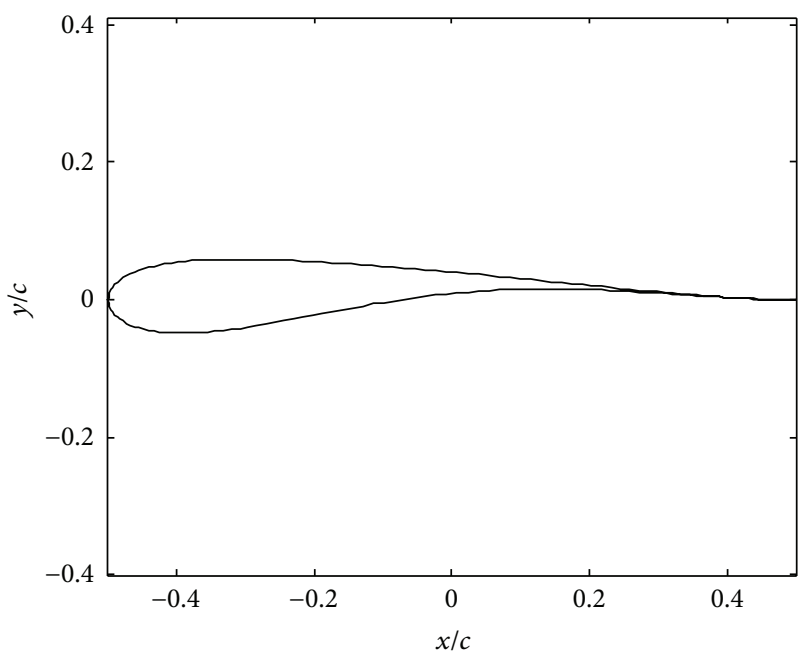

FIGURE 3: Third type of airfoil profiles.

From Figures 1-3, it is seen that the three shapes obtained from the integrated expression have the basic characteristics of an airfoil.

2.3. Generality of the Trigonometric Expression. In order to show the universality of the trigonometric expression, two popular airfoils, the NACA 64418 and the S809 airfoils, are constructed using the present analytical expression.

Combining (2) and (4), $\psi$ and $\theta$ can be expressed in terms of $x$ and $y$ as

$$
\begin{aligned}
& \cosh \varphi=\frac{x}{2 a \cos \theta}, \\
& \sinh \varphi=\frac{y}{2 a \sin \theta}, \\
& 2 \sin ^{2} \theta=p+\sqrt{p^{2}+\left(\frac{y}{a}\right)^{2}},
\end{aligned}
$$

TABLE 1: Coefficients for determining the NACA 64418 and S809 airfoils.

\begin{tabular}{lcc}
\hline Airfoils & NACA 64418 & S809 \\
\hline$a_{1}$ & 0.89482 & 1.47486 \\
$b_{1}$ & 0.04960 & 0.04733 \\
$a_{2}$ & -0.35665 & -0.55641 \\
$b_{2}$ & -0.35445 & -0.65773 \\
$a_{3}$ & -0.02444 & -0.07436 \\
$b_{3}$ & -0.01001 & -0.05212 \\
\hline
\end{tabular}

where $p=1-(x / 2 a)^{2}-(y / 2 a)^{2}$. If the coordinates $x$ and $y$ of an existing airfoil are known, the coefficients of (5) can be determined from (9). If we know $n$ points on an airfoil surface, the airfoil shape can be determined in principle with the first $n$ coefficients (5). When the number of coefficients is big, the computing time will be long. This is not very convenient for optimizations. In order to use a small number of coefficients in the expression and represent airfoil shapes with a sufficient accuracy, only the first six coefficients of the equation are chosen:

$$
\begin{aligned}
\varphi(\theta)= & a_{1}(1-\cos \theta)+b_{1} \sin \theta+a_{2}(1-\cos \theta)^{2} \\
& +b_{2} \sin ^{2} \theta+a_{3}(1-\cos \theta)^{3}+b_{3} \sin ^{3} \theta .
\end{aligned}
$$

Using the profile data of the NACA 64418 or the S809 airfoils, we choose six key data points that approximately can determine the shape of the airfoil. Putting the coordinates $(x, y)$ of these six points into (9), the values of $\varphi$ can be determined. The six coefficients $\left[a_{1}, b_{1}, a_{2}, b_{2}, a_{3}, b_{3}\right]$ are obtained as shown in Table 1 . In order to analyse the quality of the airfoil derived from the reduced expression, the NACA 64418 and S809 airfoils are reproduced using (1), (2), (4), and (10). Figure 4 shows the reproduced and the original NACA 64418 and S809 airfoils. From the figure, it is seen that the integrated expression can express the two airfoils with an acceptable accuracy. It is worth noting that a different choice of the six key points results in different six coefficients and a different airfoil shape. If a higher accuracy is required, more coefficients are needed. Thus, we can conclude that a general airfoil can be represented by the introduced expression using a relatively limited number of coefficients.

\section{Integrated Design Method}

The integrated design method presented in this paper is an optimization design method which includes an optimization process using the shape expression to represent the profiles of the airfoil. Six coefficients are chosen as design variables to represent the shape of the airfoil. The lift and drag coefficients, which are the main design objectives, are calculated using the fast and robust XFOIL code by Drela [14].

3.1. Design Objective. An important element during the airfoil design procedure is the criteria for a high lift and a low drag which can increase the energy capture and reduce the 


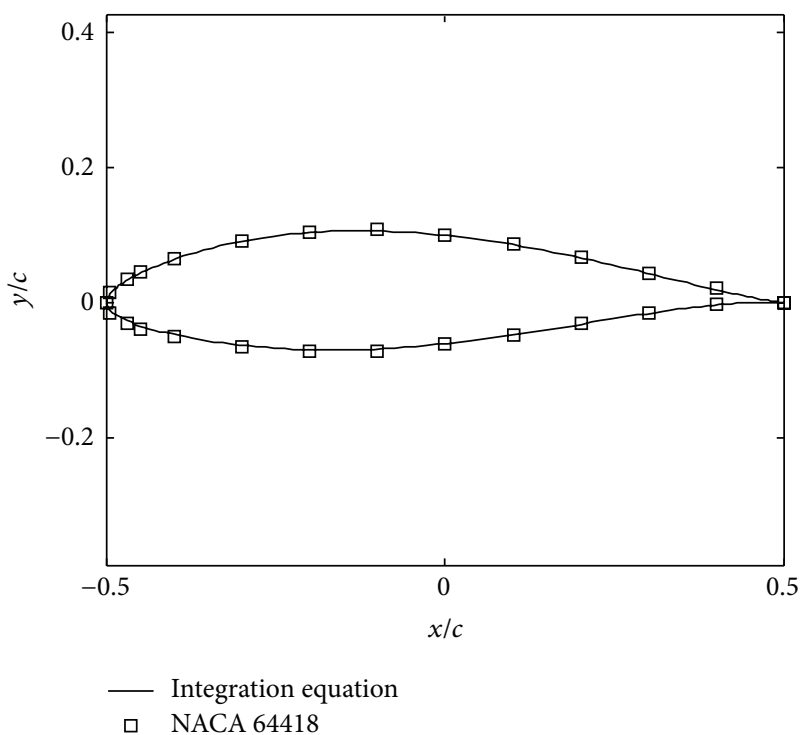

(a)

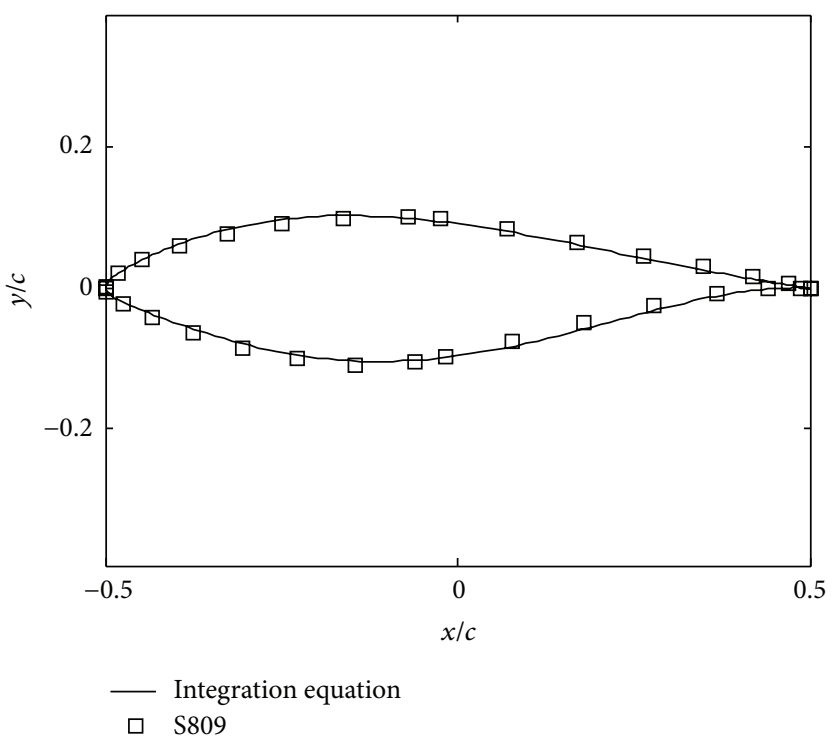

(b)

FIGURE 4: Plots of the airfoil shapes obtained with the integrated expression: (a) NACA 64418 airfoil; (b) S809 airfoil.

cost of energy. In most cases, it is desirable to obtain a high lift and drag ratio in the design $\alpha$ range. Therefore, the design objective in the study is the maximum ratio of lift and drag coefficients, $c_{l} / c_{d}$,

$$
f=\max \left(\frac{c_{l}}{c_{d}}\right)
$$

3.2. Design Variables and Constraints. As it is known that high roughness on an airfoil can cause earlier transition to turbulence, keeping the airfoil shape smooth is essential in the optimization. From the previous sections, it was shown that the shape of an airfoil can be expressed analytically using the trigonometric expression. This also implies that analytical expression results in a smooth airfoil shape. In a usual optimization procedure for airfoils, the design variables are chosen to be a spline that can control the shape of airfoil. In the present study, the coefficients of the shape expression are chosen to be the design variables.

Since the analytical expression can express airfoil shapes with the first six coefficients and the optimization with a small number of design variables can run fast, the first six coefficients are used to design airfoils. It means that only the following coefficients are active:

$$
X=\left[a_{1}, b_{1}, a_{2}, b_{2}, a_{3}, b_{3}\right] .
$$

In order to design airfoils, the basic structural features of the airfoil shape need to be satisfied. The airfoil thicknessto-chord ratio is one of the most important parameters to determine the basic structure. Besides, the location of the maximum thickness is also important. The location of the maximum thickness is always controlled to be located between $20 \%$ and $40 \%$ of the airfoil chord, measured from the leading edge [18]. Therefore, the constraint of the location of the maximum thickness is applied as

$$
0.2 \leq \frac{x}{c} \leq 0.4
$$

\section{Results and Discussion}

The optimization design of airfoil profiles is achieved by solving the function expression model using MATLAB. And, in this section, three new airfoils CQ-A15, CQ-A18, and CQA21 with a thickness of $15 \%, 18 \%$, and $21 \%$, respectively, are designed by the integrated design method. The aerodynamic performance of the designed airfoils is calculated by the XFOIL code and compared to that of a few existing wind turbine airfoils, such as the RIS $\varnothing$, DU, FFA, and NACA airfoils.

4.1. Characteristics of the New Designed Airfoils. The three new airfoils are designed to have a high lift-drag ratio $c_{l} / c_{d}$ for an attack angle $\alpha \in\left[2^{\circ}, 10^{\circ}\right]$. For airfoils with $0.15,0.18$, and 0.21 thickness-chord ratios used for constructing the outboard part of a wind turbine blade and play an important role for the output power. Table 2 lists the characteristics of the three airfoils, where $t$ is airfoil thickness, $t / c$ is thicknessto-chord ratio, and Re is Reynolds number.

Figure 5 shows the shape of the CQ-A15 airfoil with a thickness-chord ratio of 0.15 . The location of the maximum thickness of this airfoil is at 0.25 chords from the leading edge. The airfoil has a maximum lift coefficient of 1.86 and a maximum lift-drag ratio of 143.92 at a Reynolds number $\operatorname{Re}=1.6 \times 10^{6}$. The maximum lift coefficient is found at an attack angle of about $18^{\circ}$ and the maximum lift-drag ratio is located at an attack angle of about $6.5^{\circ}$. Figure 6 shows the 
TABLE 2: Geometric parameters of the designed airfoils.

\begin{tabular}{ccccc}
\hline \multicolumn{5}{c}{ Designed airfoil } \\
$t / c$ & $x / c$ at $\max t / c$ & $\operatorname{Re} \times 10^{6}$ & $\max c_{l}$ & $\max \left(c_{l} / c_{d}\right)$ \\
\hline 0.15 & 0.25 & 1.6 & 1.86 & 143.92 \\
0.18 & 0.25 & 1.6 & 1.87 & 150.09 \\
0.21 & 0.23 & 1.6 & 1.96 & 130.10 \\
\hline
\end{tabular}

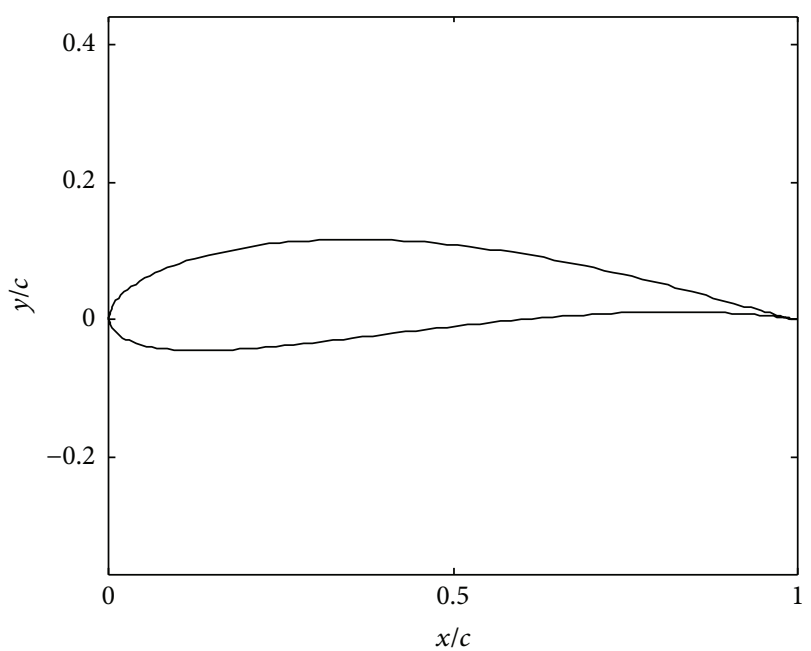

FIGURE 5: The new designed CQ-A15 airfoil with a thickness-chord ratio of 0.15 .

shape of the CQ-A18 airfoil with thickness-chord ratio of 0.18 . The location of the maximum thickness of this airfoil is at 0.25 chords from the leading edge. The airfoil has a maximum lift coefficient of 1.87 and a maximum lift-drag ratio of 150.09 at a Reynolds number Re $=1.6 \times 10^{6}$. The maximum lift coefficient is found at an attack angle of about $18^{\circ}$ and the maximum lift-drag ratio is located at an attack angle of about $5.5^{\circ}$. The shape of the designed airfoil with thicknesschord ratio of 0.21 is shown in Figure 7. The location of the maximum thickness of this airfoil is at 0.23 chords. The airfoil has a maximum lift coefficient of 1.96 and a maximum liftdrag ratio of 130.10 at $\mathrm{Re}=1.6 \times 10^{6}$. The maximum lift coefficient of the CQ-A21 is found at an attack angle of $18^{\circ}$ and the maximum lift-drag ratio appears at an attack angle of $6^{\circ}$.

4.2. Aerodynamic Performance of the New Airfoils and Comparisons to Existing Airfoils. All results shown here are carried out using the viscous-inviscid interactive XFOIL code. In order to analyse the sensitivity of the new airfoils to turbulent inflow and wall roughness, computations for both free transitional and fully turbulent flows at $\mathrm{Re}=1.6 \times 10^{6}$ are carried out. Figure 8 shows the lift coefficient $c_{l}$ and the lift-drag relation of the new CQ-A15 airfoil. From the figure, it is seen that the lift coefficient is not very sensitive to the inflow turbulence level but the lift-drag ratio is decreased for turbulent flow. The maximum $c_{l}$ and $c_{l} / c_{d}$ for fully turbulent

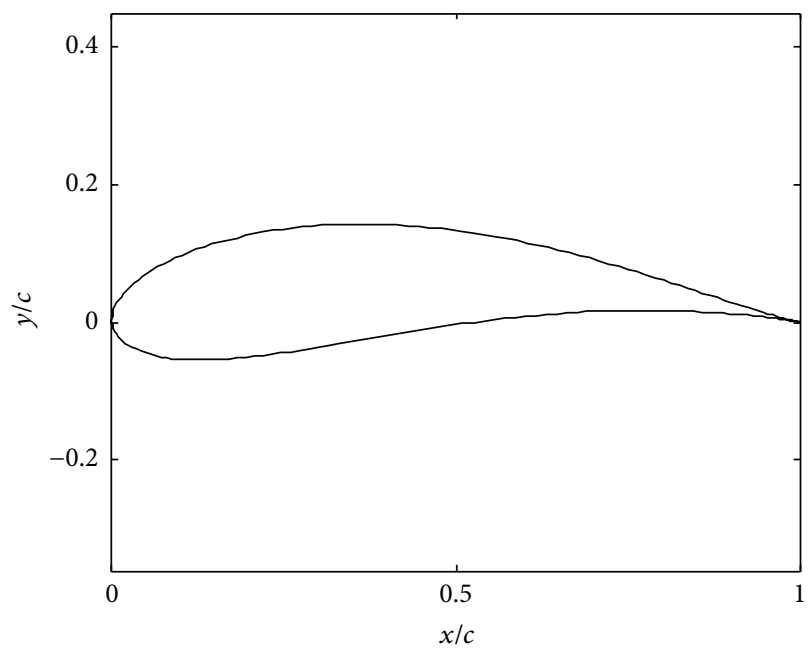

FIgURE 6: The new designed CQ-A18 airfoil with a thickness-chord ratio of 0.18 .

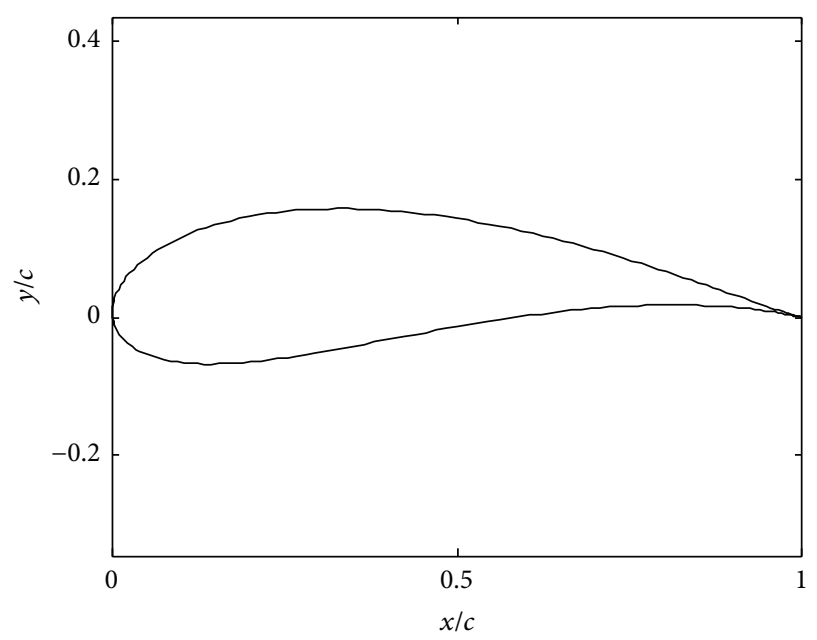

FIGURE 7: The new designed CQ-A21 airfoil with a thickness-chord ratio of 0.21 .

flow are estimated to be 1.83 and 116.76. Figure 9 shows the lift coefficient $c_{l}$ and the lift-drag relation of the new CQA18 airfoil. From the figure, it is seen that the lift coefficient is slightly more sensitive to inflow turbulence. The changes in lift-drag ratio are very similar to the CQ-A15 airfoil. The maximum $c_{l}$ and $c_{l} / c_{d}$ for fully turbulent flow are reduced to 1.82 and 127.67. Figure 10 shows the lift and drag coefficients $c_{l}$ and $c_{d}$ of the new airfoil CQ-A21. From the figure, very similar features are seen. The maximum $c_{l}$ and $c_{l} / c_{d}$ for turbulent flow are reduced to 1.89 and 113.10 compared to free transitional flow.

In order to demonstrate the performance of the designed airfoils, a comparison is made between the new airfoils and some existing wind turbine airfoils such as RIS $\emptyset$, DU, NACA, and FFA airfoils. A data base of force characteristics on the existing airfoils is presented by Bertagnolio et al. $[19,20]$ using 


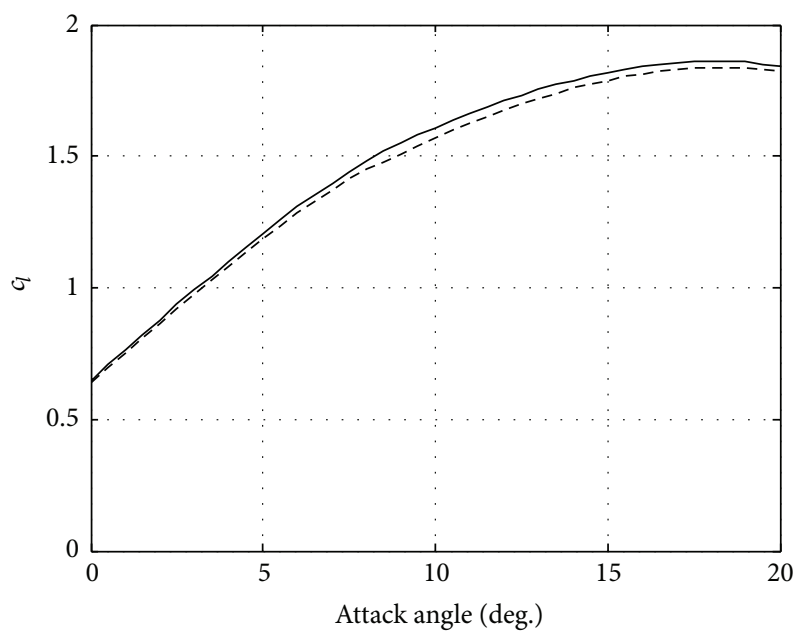

- Free transition - - - Turbulent flow

(a)

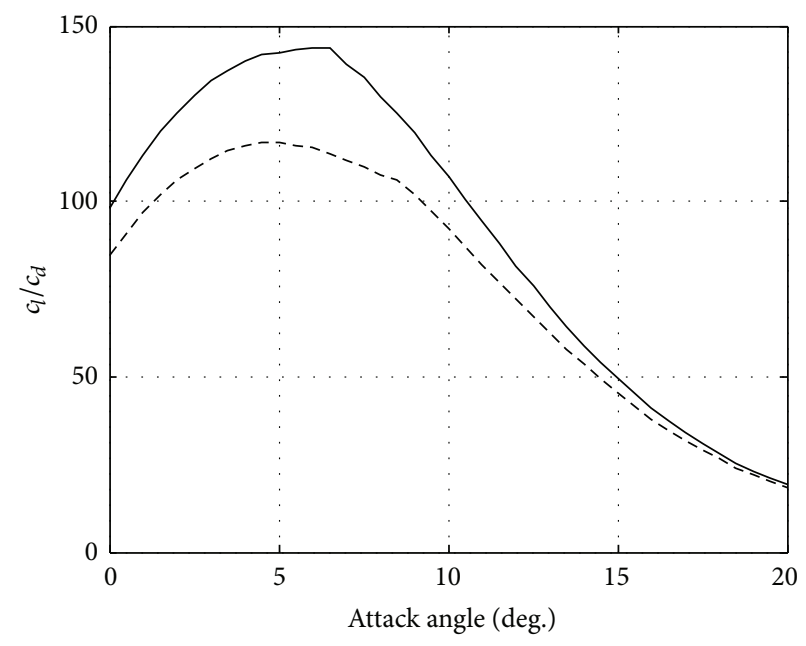

- Free transition - - - Turbulent flow

FIGURE 8: Lift coefficient $c_{l}$ (a) and lift-drag ratio (b) for the new designed airfoil CQ-A15 at $\operatorname{Re}=1.6 \times 10^{6}$.

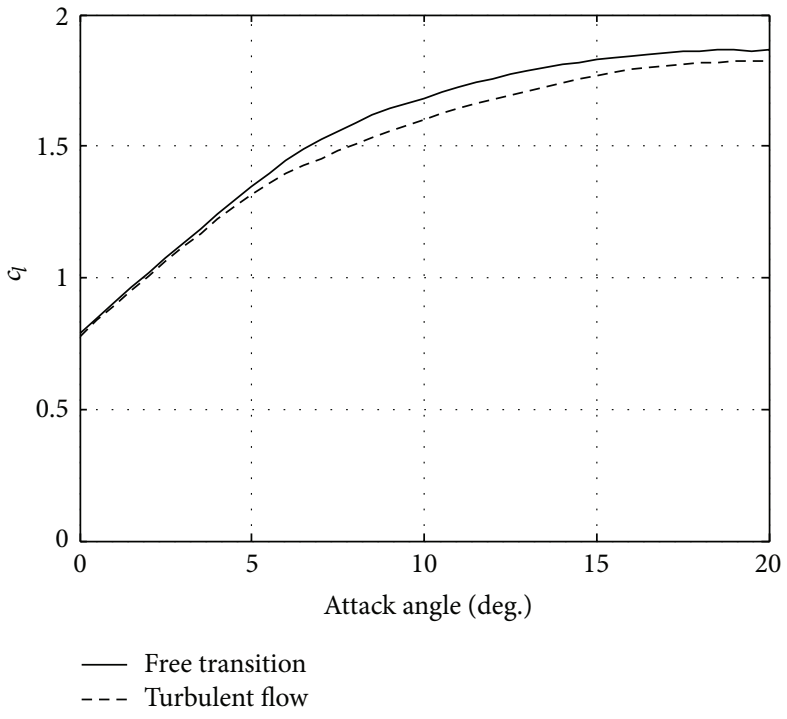

(a)

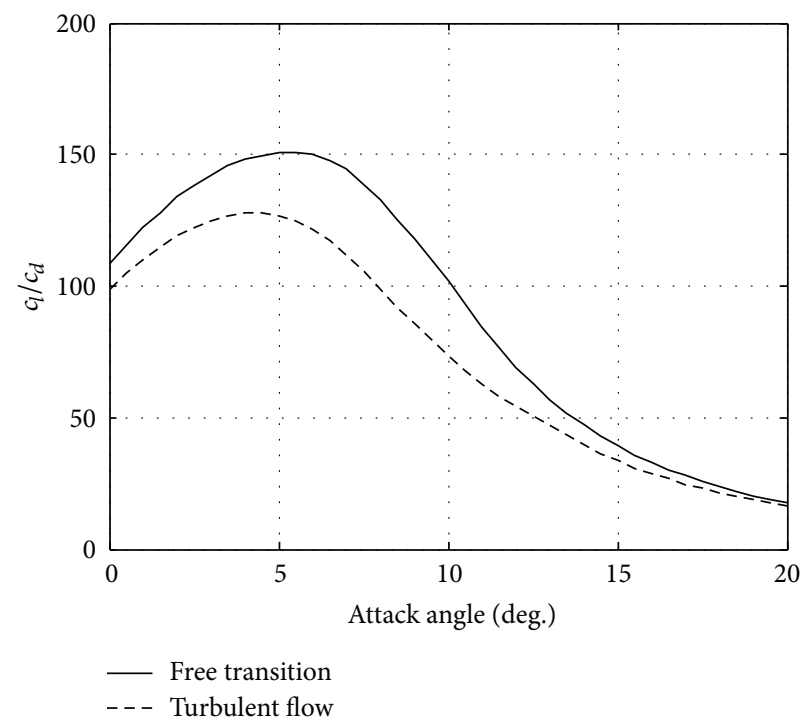

(b)

FIGURE 9: Lift coefficient $c_{l}$ (a) and lift-drag ratio (b) for the new designed airfoil CQ-A18 at Re $=1.6 \times 10^{6}$.

the XFOIL code. Figure 11 shows the lift and drag coefficients $c_{l}$ and $c_{l} / c_{d}$ for the new designed CQ-A15 airfoil and the NACA 63215 airfoil at $\operatorname{Re}=1.09 \times 10^{6}$. From the figure, it is seen that the lift coefficients for the CQ-A15 airfoil increase monotonously for attack angle ranging between $0^{\circ}$ and $20^{\circ}$, but the lift coefficients of the NACA 63215 airfoil start to decrease at an attack angle of $17^{\circ}$ and also the $c_{l}$ values are much smaller than that of the new design airfoil. The drag coefficients are similar for both airfoils. Due to the higher lift coefficient $c_{l}$ of the new airfoil, the lift-drag ratio $c_{l} / c_{d}$ is also much bigger than that of the NACA 63215 airfoil.
Figure 12 shows the lift and drag coefficients $c_{l}$ and $c_{l} / c_{d}$ for the CQ-A18 airfoil and the NACA 64418 airfoil at Re = $1.6 \times 10^{6}$. From the figure, similar features are seen where the lift coefficients for both airfoils increase monotonously for attack angle ranging between $0^{\circ}$ and $20^{\circ}$, but the lift coefficient of the new designed airfoil is much higher than that of the NACA 64418 airfoil. The drag coefficients are also similar for both airfoils. As it is in the previous comparison, the liftdrag ratio $c_{l} / c_{d}$ is also much bigger than that of the NACA 64418 airfoil. Figure 13 shows the lift coefficient $c_{l}$ and liftdrag ratio $c_{l} / c_{d}$ at $\operatorname{Re}=1.6 \times 10^{6}$ for the new designed CQ-A18 


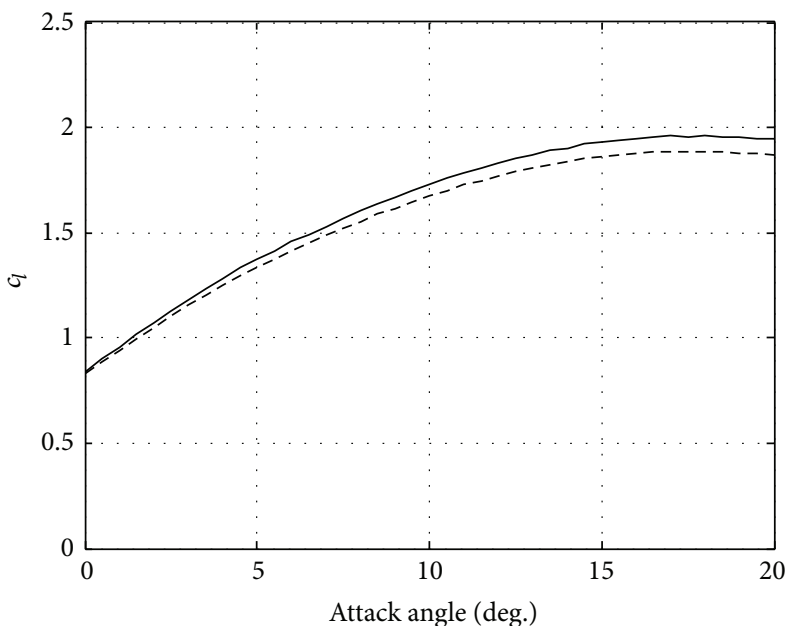

Free transition

_. _ Turbulent flow

(a)

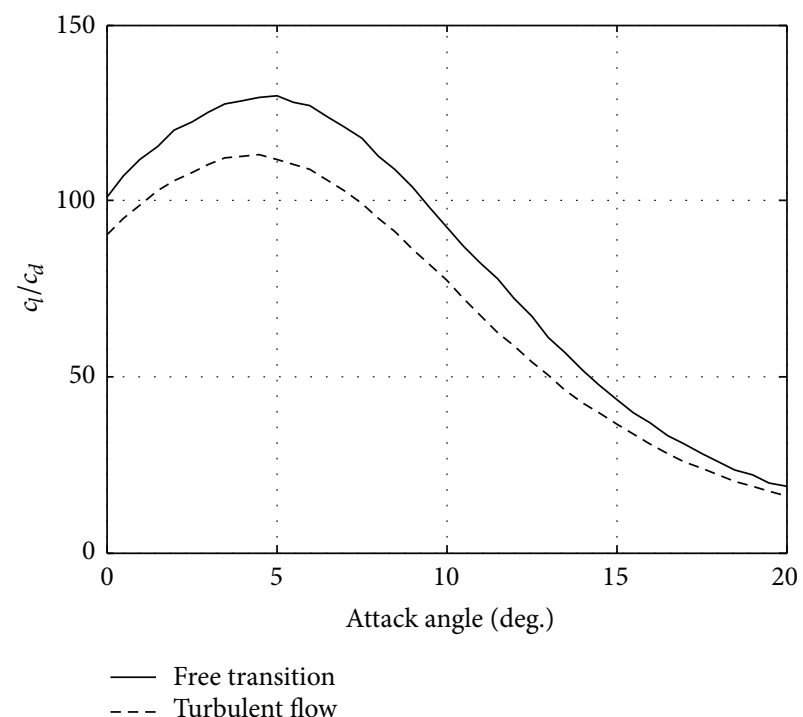

(b)

Figure 10: Lift coefficient $c_{l}$ (a) and lift-drag ratio (b) for the new designed airfoil CQ-A21 at Re $=1.6 \times 10^{6}$.

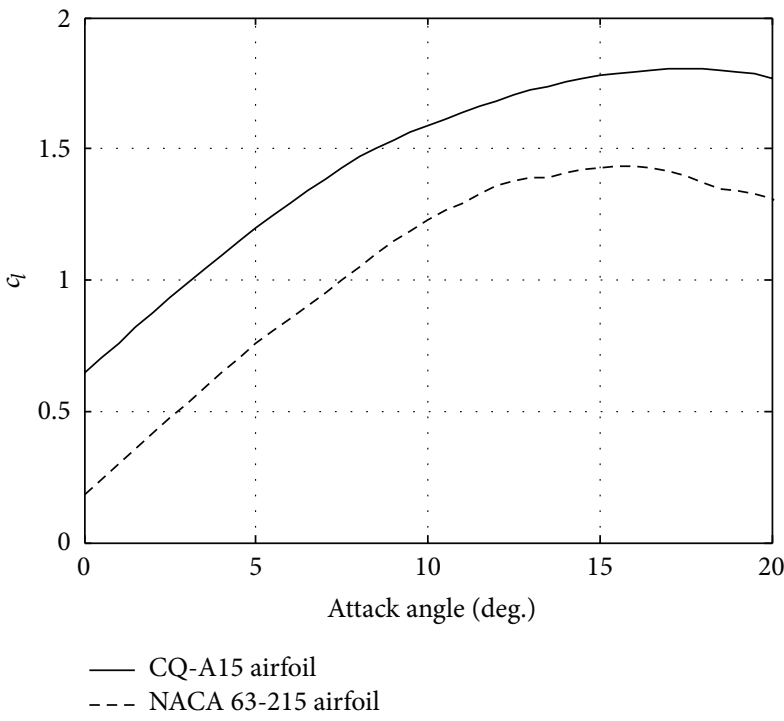

(a)

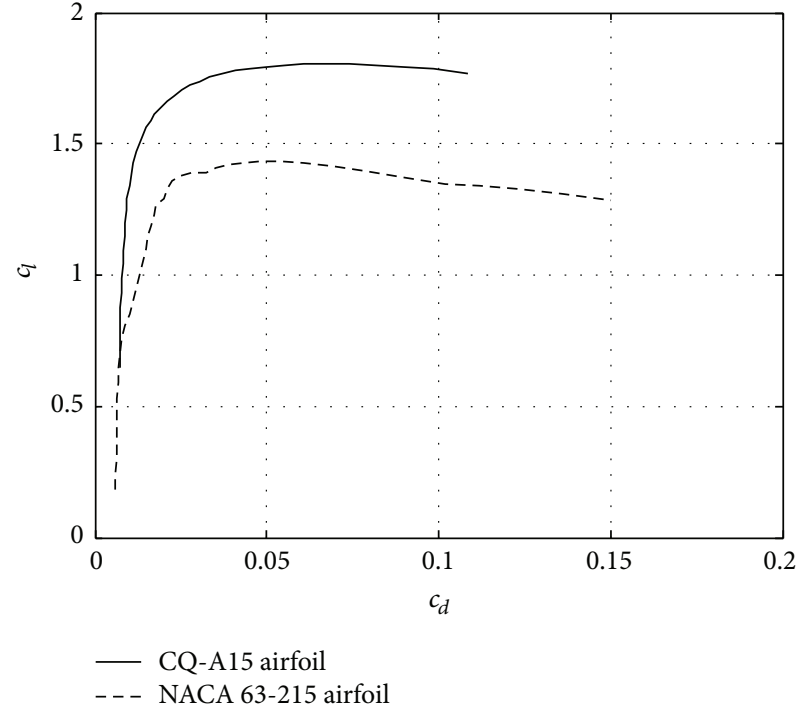

(b)

FIGURE 11: Lift coefficient $c_{l}$ (a) and lift-drag chart (b) for flows past the new CQ-A15 airfoil and past the NACA 63215 airfoil at Re $=1.09 \times 10^{6}$.

airfoil and the RISØ-A1-18 airfoil which have the same relative thickness. From the figure, it is seen that the new designed airfoil produces a higher lift coefficient $c_{l}$ for an attack angle ranging between $0^{\circ}$ and $20^{\circ}$. It is worth noting that the lift coefficient $c_{l}$ of the RIS $\varnothing$-Al-18 airfoil decreases at an attack angle of $12^{\circ}$.

Similar comparisons for the $21 \%$ thickness airfoil CQA21 are shown below. Figure 14 shows the aerodynamic performance of the new CQ-A21 airfoil and the RIS $\emptyset$-A1-21 airfoil with the same thickness-chord ratio at $\mathrm{Re}=1.6 \times 10^{6}$. The RIS $\varnothing$-A1-21 airfoil stalls at $\alpha=12^{\circ}$ where the lift suddenly decreases and the drag increases. The lift coefficient $c_{l}$ of the new airfoil is seen to reach a value of about 2.0. When the lift coefficient $c_{l}$ reaches 2 , the drag coefficient $c_{d}$ starts to increase quickly. Figure 15 shows the aerodynamic performance of the CQ-A21 airfoil and the DU93-W-210 airfoil at $\operatorname{Re}=1.0 \times 10^{6}$. From the figure, it is obvious that the designed airfoil attains a much bigger $c_{l}$ during the whole attack angle range between $0^{\circ}$ and $20^{\circ}$, but the slopes of the lift coefficient $c_{l}$ against the angle of attack $\alpha$ are similar. The drag coefficient $c_{d}$ for the two airfoils is very similar at angle of attack up to stall. Since a bigger $c_{l}$ is obtained for the new airfoil, the lift-drag ratio 


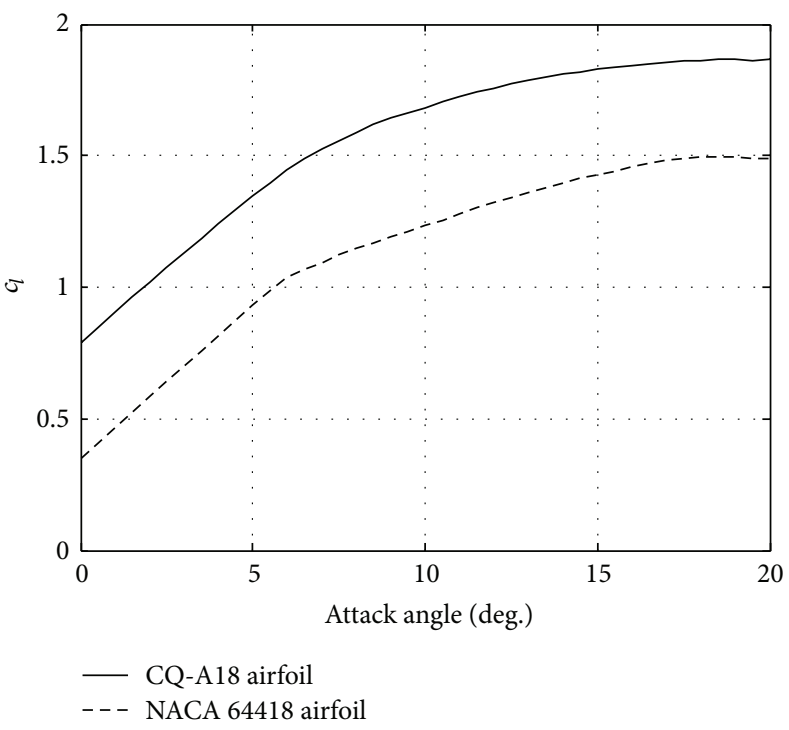

(a)

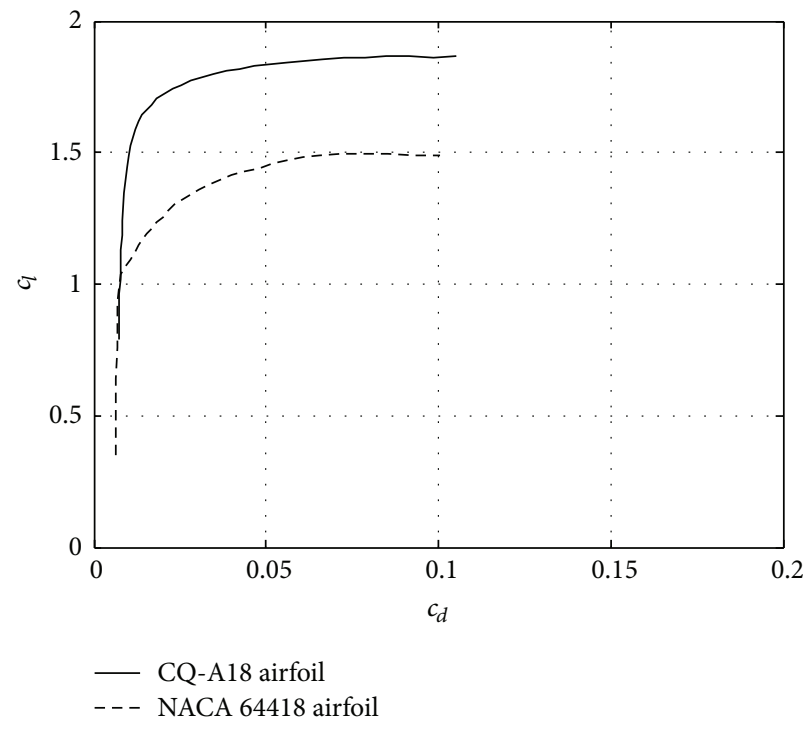

(b)

FIGURE 12: Lift coefficient $c_{l}$ (a) and lift-drag chart (b) for flows past the new CQ-A18 airfoil and past the NACA 64418 airfoil at Re $=1.6 \times 10^{6}$.

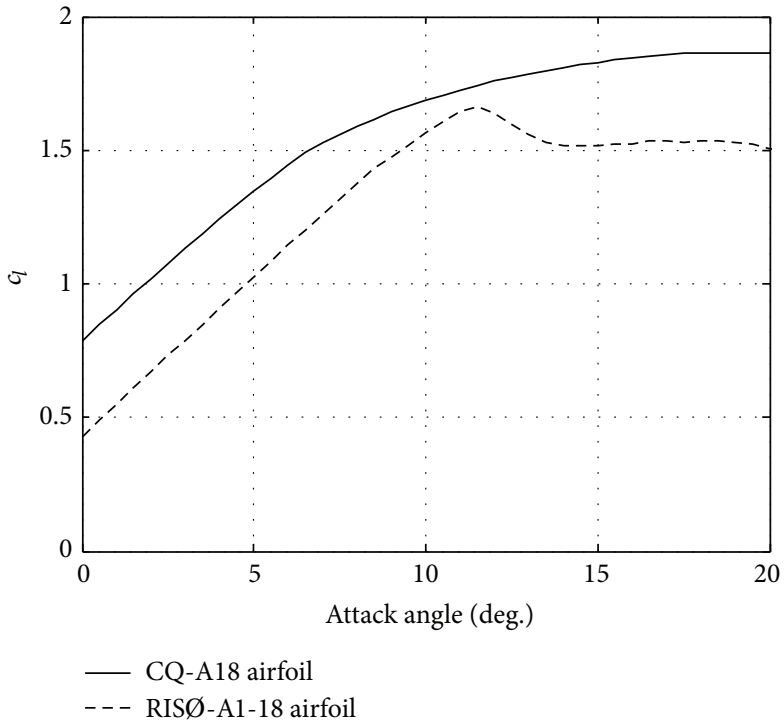

(a)

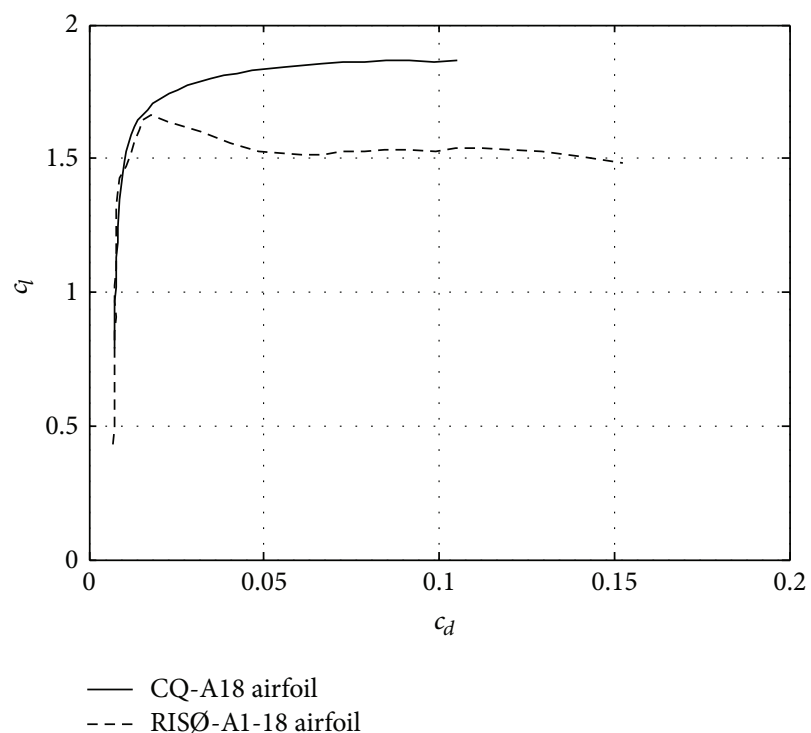

(b)

FIGURE 13: Lift coefficient $c_{l}$ (a) and lift-drag chart (b) for flows past the new CQ-A18 airfoil and past the RIS $\varnothing$-A1-18 airfoil at Re $=1.6 \times 10^{6}$.

$c_{l} / c_{d}$ of the new designed airfoil is also bigger than that of the DU93-W-210 airfoil. Figure 16 shows the aerodynamic performance between the CQ-A21 airfoil and the FFA-W3-211 airfoil at $\mathrm{Re}=1.8 \times 10^{6}$. Compared to the FFA-W3-211 airfoil, the lift coefficient $c_{l}$ of the new designed airfoil is much bigger whereas the drag coefficients $c_{d}$ for both airfoils are similar. It means that the lift-drag ratio $c_{l} / c_{d}$ of the designed airfoil is much bigger than that of the FFA-W3-211 airfoil.

4.3. Roughness Sensitivity Study for the New Airfoils. Roughness in the region near the airfoil leading edge is formed by accumulation of dust, dirt, and bugs which can lead to premature transition in the laminar boundary layer and result in earlier separation. To simulate the influence of roughness on the performance of an airfoil, the fixed-transition on the upper and lower surfaces is usually used. In the RIS $\varnothing$ experiments $[21,22]$, transition was fixed at $5 \%$ and $10 \%$ on the upper and lower surfaces, respectively.

In order to test the sensitivity of the new airfoils, transition was fixed at the same locations: $5 \%$ and $10 \%$ on the upper and lower surfaces, respectively. The lift and drag coefficients of the new three airfoils were calculated using 


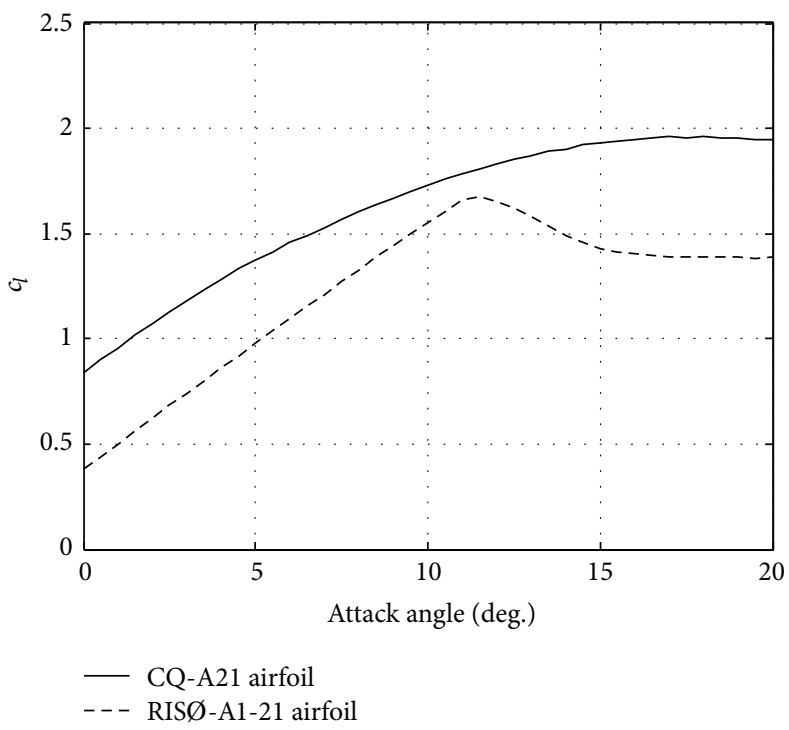

(a)

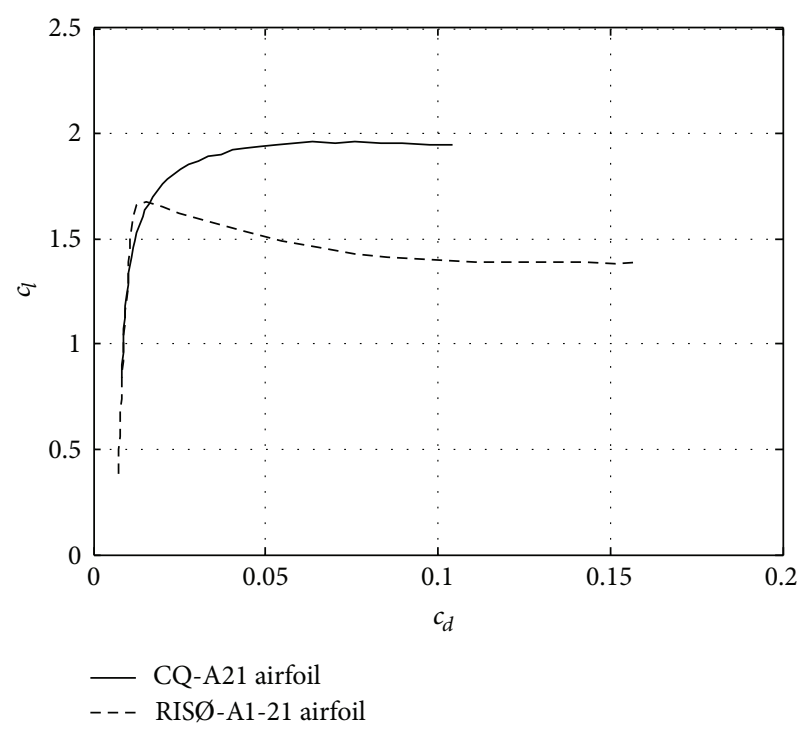

(b)

FIGURE 14: Lift coefficient $c_{l}$ (a) and lift-drag chart (b) for flows past the new CQ-A21 airfoil and past the RIS $\varnothing$-A1-21 airfoil at Re $=1.6 \times 10^{6}$.

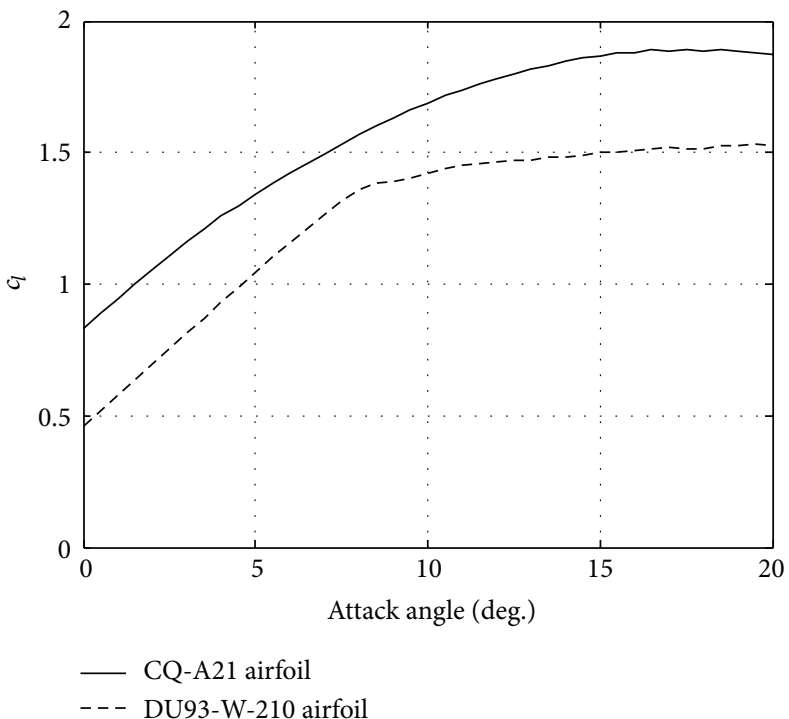

(a)

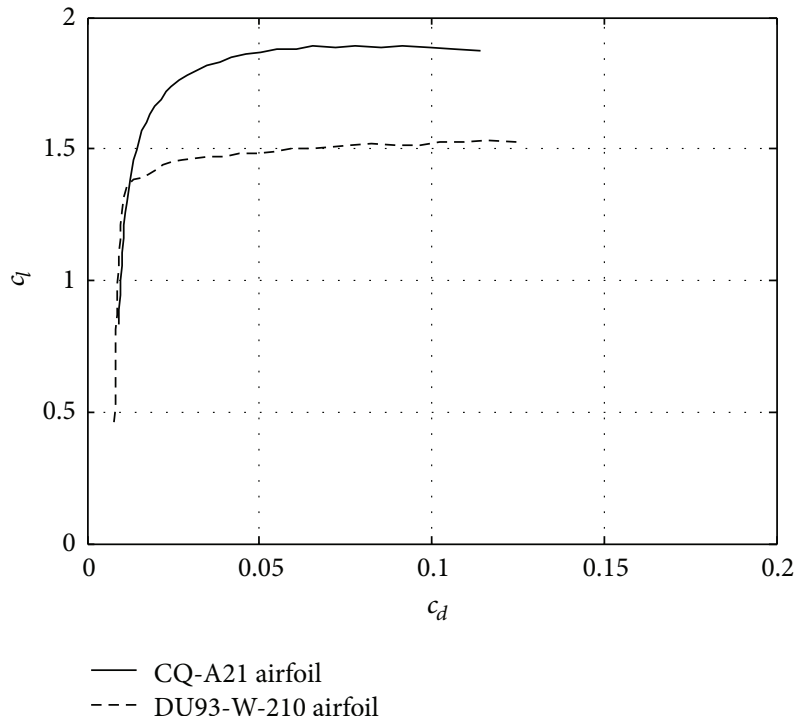

(b)

FIGURE 15: Comparison of the lift coefficient $c_{l}$ (a) and the lift-drag ratio $c_{l} / c_{d}$ (b) obtained for flows past the CQ-A21 airfoil and past the DU93-W-210 airfoil at $\operatorname{Re}=1.0 \times 10^{6}$.

the XFOIL code. In Figure 17, the performances of the CQA15 airfoil with both clean and rough walls are plotted. It is seen that, for the rough airfoil, the lift coefficient is slightly smaller than that of the clean airfoil, but the maximum values are almost the same. Figure 18 shows the comparison of the performances of the CQ-A18 airfoil with clean and rough walls. From the figure, it is seen that the lift coefficient of the rough airfoil is significantly smaller than the clean airfoil, especially at angle of attack between $5^{\circ}$ and $15^{\circ}$. It should be noted that the drag coefficient at fixed transition is bigger than the free transition case. Similarly, Figure 19 shows the results for CQ-A21 airfoil. From the figure, it is seen that the lift coefficient is decreased and the drag coefficient is increased for the rough airfoil comparing to the clean airfoil.

\section{Conclusions}

In this paper a new integrated design method for wind turbines airfoils using an analytical expression of series and conformal transformations has been developed. Using this 


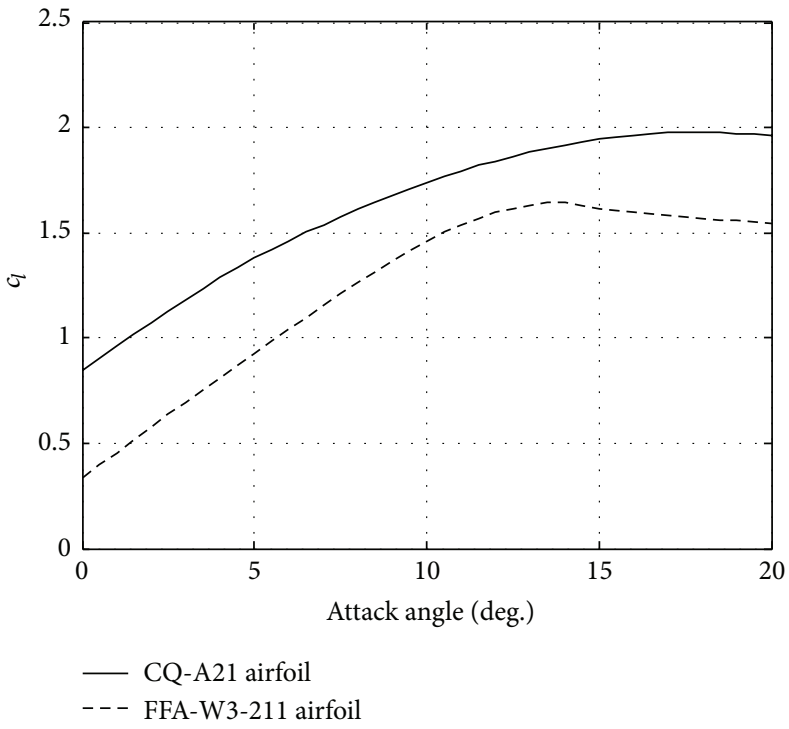

(a)

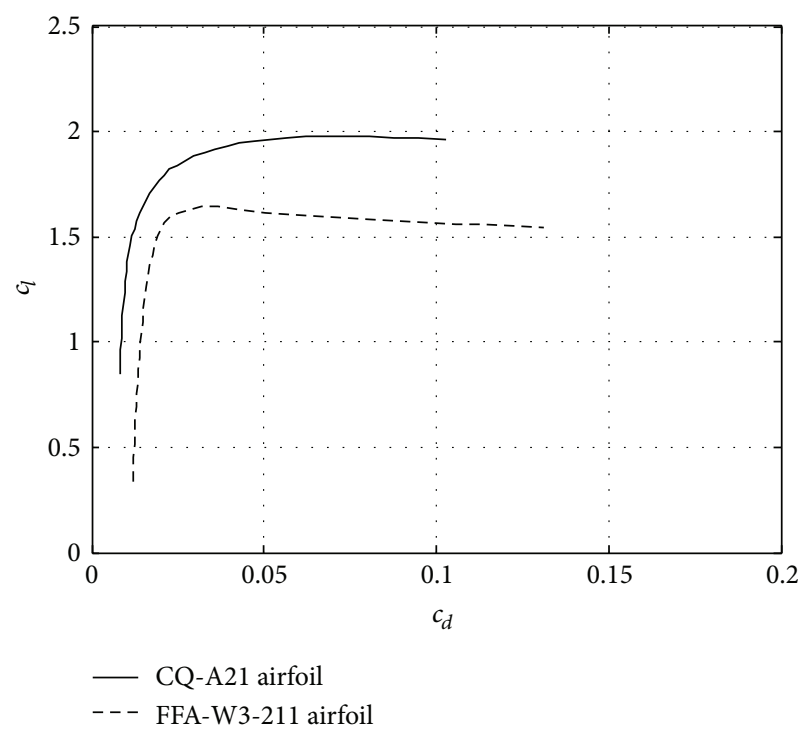

(b)

FIGURE 16: Comparison of the lift coefficient $c_{l}$ (a) and the lift-drag ratio $c_{l} / c_{d}$ (b) for flows past the CQ-A21 airfoil and past the FFA-W3-211 airfoil at $\operatorname{Re}=1.8 \times 10^{6}$.

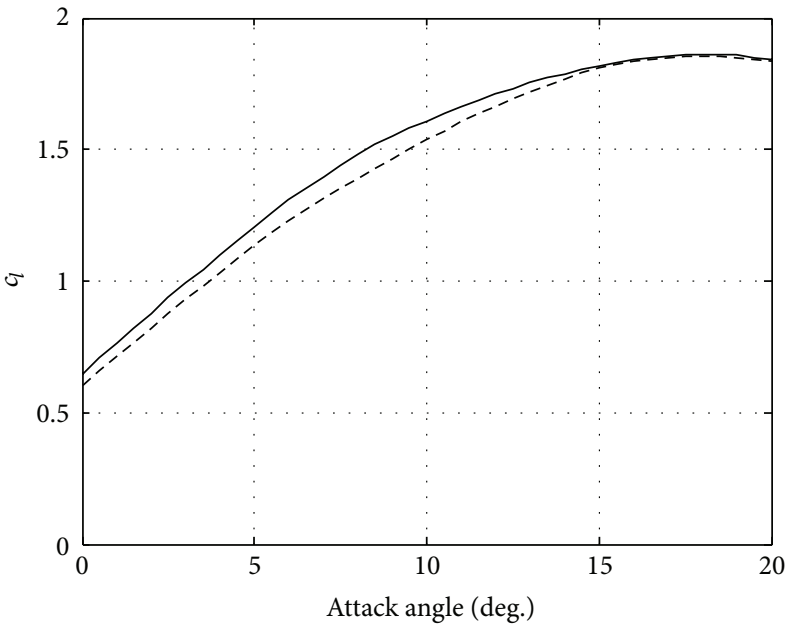

Clean airfoil

- - - Rough airfoil

(a)

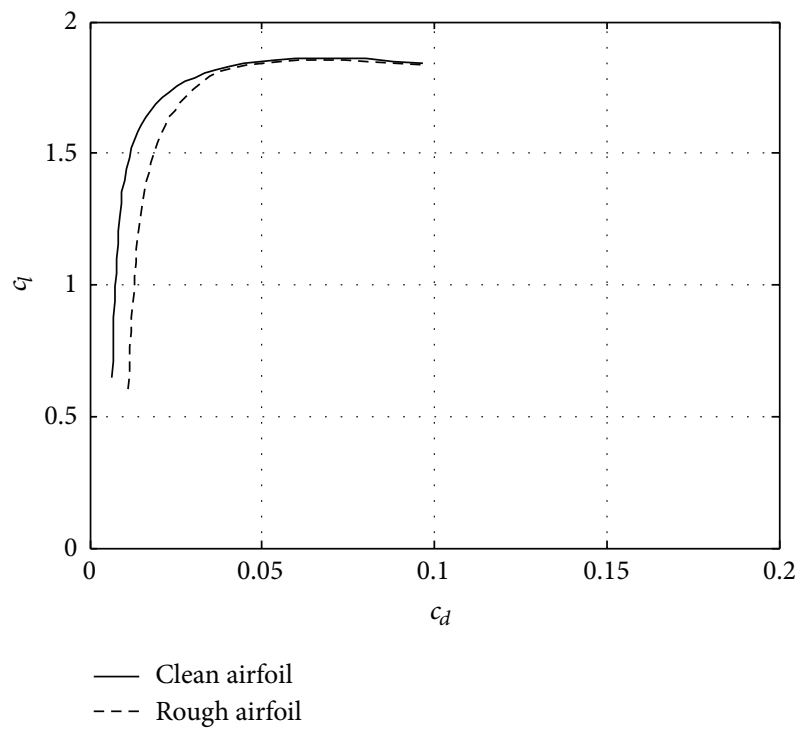

(b)

FIGURE 17: Lift coefficient $c_{l}$ (a) and lift-drag chart (b) for the new CQ-A15 airfoil with clean and rough walls at $\operatorname{Re}=1.6 \times 10^{6}$.

method, three new airfoils named CQ-A15, CQ-A18, and CQA21 with a thickness-chord ratio of $0.15,0.18$, and 0.21 , respectively, are designed. The performance of the new airfoils (lift coefficient $c_{l}$ and lift-drag ratio $c_{l} / c_{d}$ ) is calculated using the XFOIL code for both free transition and fully turbulent flows at a Reynolds number of $\operatorname{Re}=1.6 \times 10^{6}$. The sensitivity on wall roughness is simulated with fixed transition on airfoil wall. Computations on the new airfoils with rough wall show that the CQ-A15 airfoil is not very sensitive on wall roughness whereas the other two airfoils are sensitive. The force characteristics of the new airfoils are also compared to the common wind turbine airfoils such as RIS $\varnothing$, DU, NACA, and FFA airfoils. The results show that the new method is feasible for designing wind turbines airfoils.

\section{Conflict of Interests}

The authors declare that there is no conflict of interests regarding the publication of this paper. 


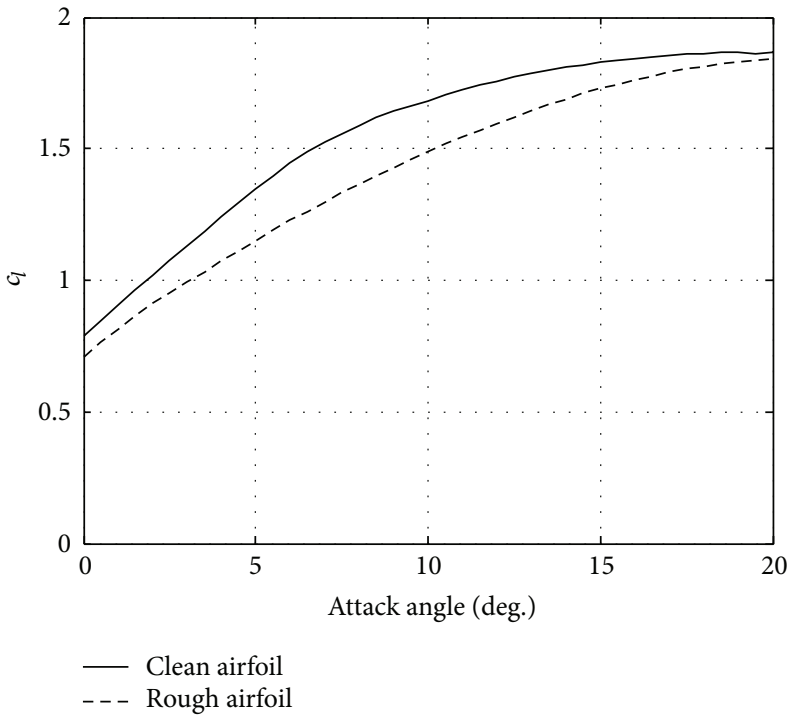

(a)

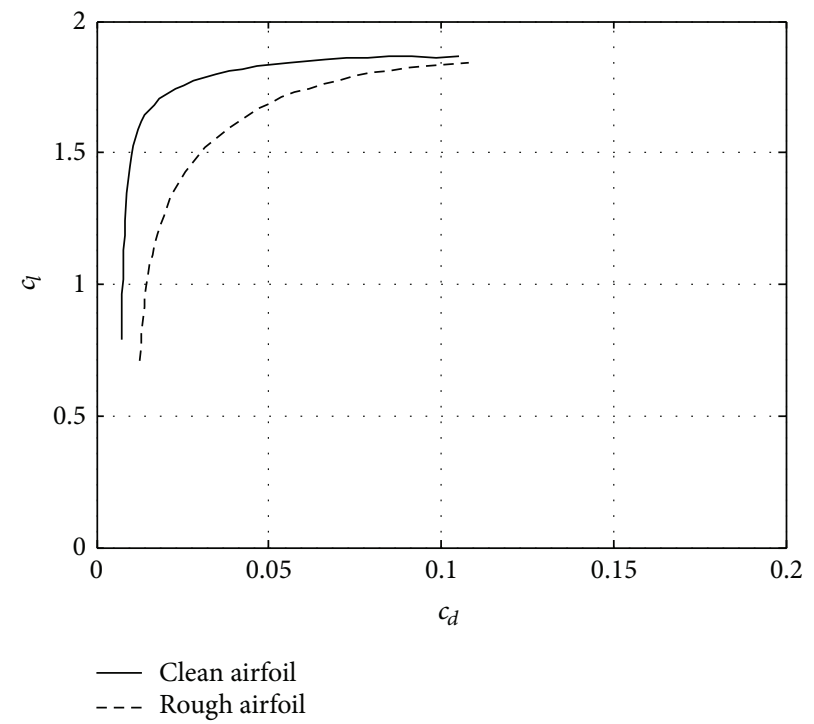

(b)

FIGURE 18: Lift coefficient $c_{l}$ (a) and lift-drag chart (b) for the new CQ-A18 airfoil with clean and rough walls at $\operatorname{Re}=1.6 \times 10^{6}$.

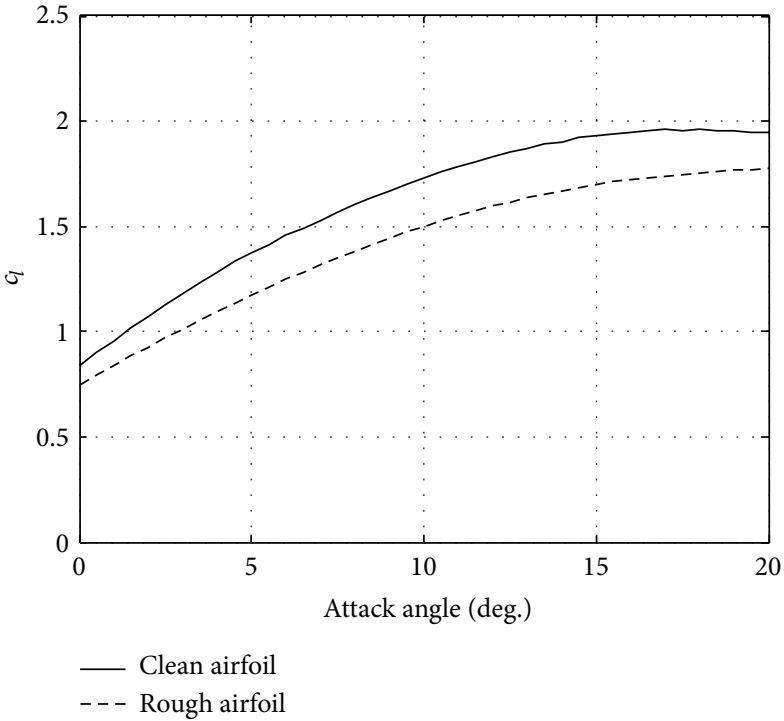

(a)

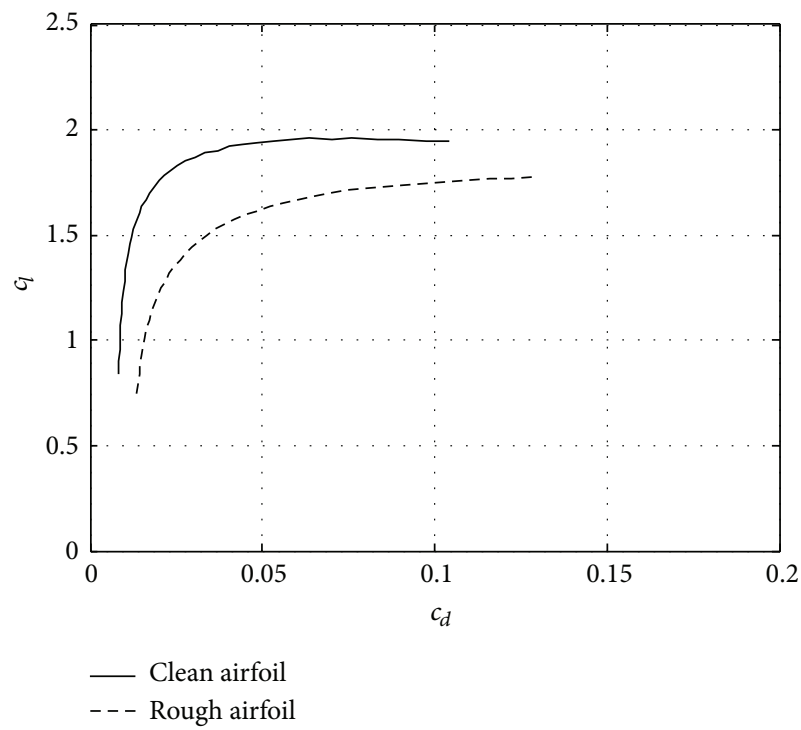

(b)

FiguRE 19: Lift coefficient $c_{l}$ (a) and lift-drag chart (b) for the new CQ-A21 airfoil with clean and rough walls at $\operatorname{Re}=1.6 \times 10^{6}$.

\section{Acknowledgment}

This work was supported by the National Natural Science Foundation of China (Grant no. 51205430), Natural Science Foundation of Chongqing (Grant no. cstc2011jjA70002), and China Postdoctoral Science Foundation (Grant no. 2013T60842).

\section{References}

[1] Ö. Turhan and G. Bulut, "On nonlinear vibrations of a rotating beam," Journal of Sound and Vibration, vol. 322, no. 1-2, pp. 314335, 2009.
[2] R. Eppler and D. M. Somers, "Low speed airfoil design and analysis. Advanced technology airfoil research-volume I," NASA CP-2045, Part 1, 1979.

[3] R. Eppler and D. M. Somers, "A computer program for the design and analysis of low-speed airfoils," NASA TM-80210, 1980.

[4] S. Sarkar and H. Bijl, "Nonlinear aeroelastic behavior of an oscillating airfoil during stall-induced vibration," Journal of Fluids and Structures, vol. 24, no. 6, pp. 757-777, 2008.

[5] D. N. Srinath and S. Mittal, "Optimal aerodynamic design of airfoils in unsteady viscous flows," Computer Methods in Applied Mechanics and Engineering, vol. 199, no. 29-32, pp. 1976-1991, 2010. 
[6] A. Filippone, "Airfoil inverse design and optimization by means of viscous-inviscid techniques," Journal of Wind Engineering and Industrial Aerodynamics, vol. 56, no. 2-3, pp. 123-136, 1995.

[7] K. Y. Maalawi and M. A. Badr, "A practical approach for selecting optimum wind rotors," Renewable Energy, vol. 28, no. 5, pp. 803-822, 2003.

[8] C. Bak and P. Fuglsang, "Modification of the NACA 632-415 leading edge for better aerodynamic performance," Journal of Solar Energy Engineering-Transactions of the ASME, vol. 124, no. 4, pp. 327-334, 2002.

[9] J. L. Tangler and D. M. Somers, "Status of the special-purpose airfoil families," SERI TP-217-3246, 1987.

[10] J. L. Tangler and D. M. Somers, "NREL airfoil families for HAWT's," in Proceedings of the WINDPOWER, pp. 117-123, Washington, DC, USA, 1995.

[11] W. A. Timmer and R. P. J. O. M. Van Rooij, "Summary of the Delft university wind turbine dedicated airfoils," Journal of Solar Energy Engineering, vol. 125, no. 4, pp. 488-496, 2003.

[12] P. Fuglsang, C. Bak, M. Gaunaa, and I. Antoniou, "Design and verification of the Risø-B1 airfoil family for wind turbines," Journal of Solar Energy Engineering, vol. 126, no. 4, pp. 10021010, 2004.

[13] A. Bjork, Coordinates and Calculations for the FFA-W1- $x x x$, FFA-W2- $x x x$ and FFA-w3-xxx Series of Airfoils for Horizontal Axis Wind Turbines, FFA TN, Stockholm, Sweden, 1990.

[14] M. Drela, "XFOIL: an analysis and design system for low Reynolds number airfoils," in Low Reynolds Number Aerodynamics, vol. 54 of Lecture Notes in Engineering, pp. 1-12, Springer, 1989.

[15] W. Z. Shen and J. N. Sørensen, "Quasi-3D Navier-Stokes model for a rotating airfoil," Journal of Computational Physics, vol. 150, no. 2, pp. 518-548, 1999.

[16] I. H. Abbott and A. E. Von Doenhoff, Theory of Wing Sections, Dover Publications, New York, NY, USA, 1959.

[17] V.H. Morcos, "Aerodynamic performance analysis of horizontal axis wind turbines," Renewable Energy, vol. 4, no. 5, pp. 505-518, 1994.

[18] P. Thokala and J. R. R. A. Martins, "Variable-complexity optimization applied to airfoil design," Engineering Optimization, vol. 39, no. 3, pp. 271-286, 2007.

[19] F. Bertagnolio, N. Sørensen, J. Johansen, and P. Fuglsang, "Wind turbine airfoil catalogue," Risø-R 1280(EN), Risø National Laboratory, Roskilde, Denmark, 2001.

[20] F. Bertagnolio, N. N. Sørensen, and F. Rasmussen, "New insight into the flow around a wind turbine airfoil section," Journal of Solar Energy Engineering-Transactions of the ASME, vol. 127, no. 2, pp. 214-222, 2005.

[21] P. Fuglsang and C. Bak, "Wind tunel tests of the Risø-A1-18, Risø-A1-21 and Risø-A1-24 airfoils," Report Risø-R-1112(EN), Risø National Laboratory, Roskilde, Denmark, 1999.

[22] P. Fuglsang and C. Bak, "Development of the RIS $\varnothing$ wind turbine airfoils," Wind Energy, vol. 7, no. 2, pp. 145-162, 2004. 


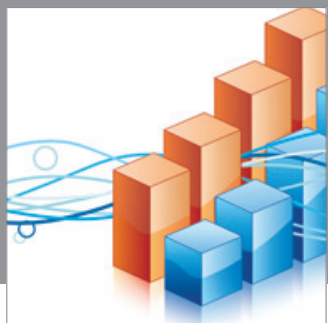

Advances in

Operations Research

mansans

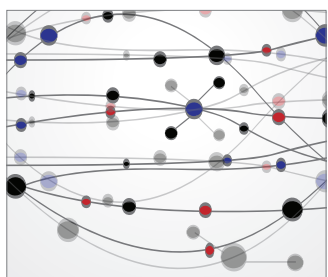

The Scientific World Journal
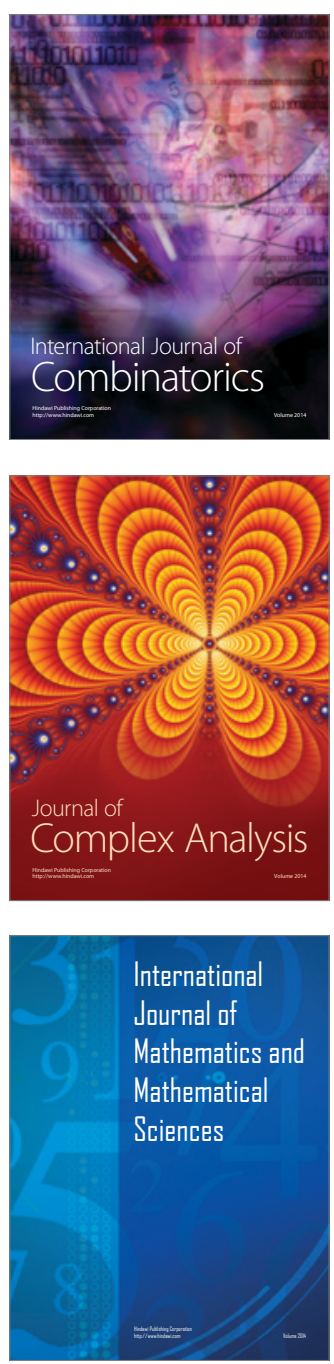
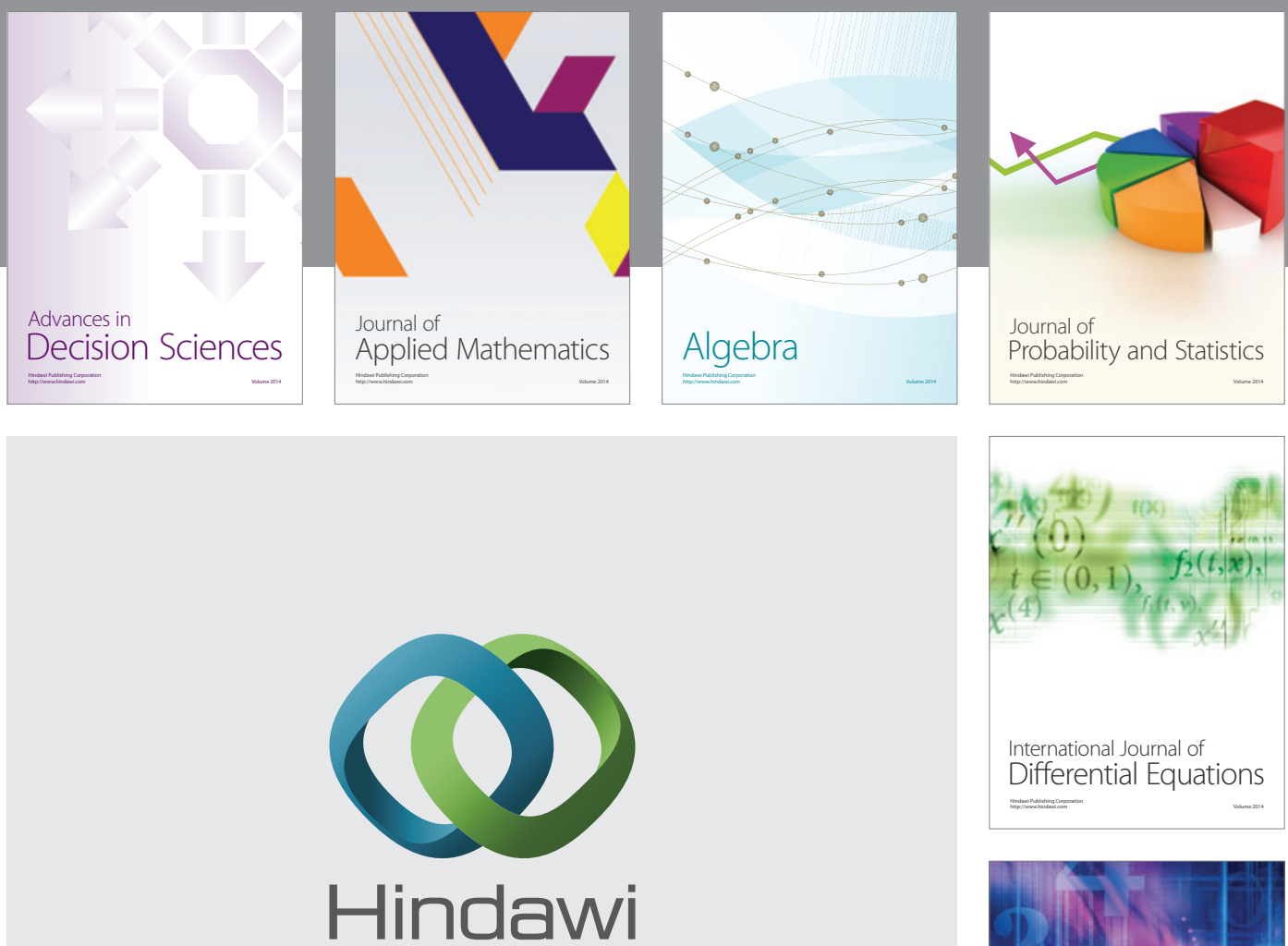

Submit your manuscripts at http://www.hindawi.com
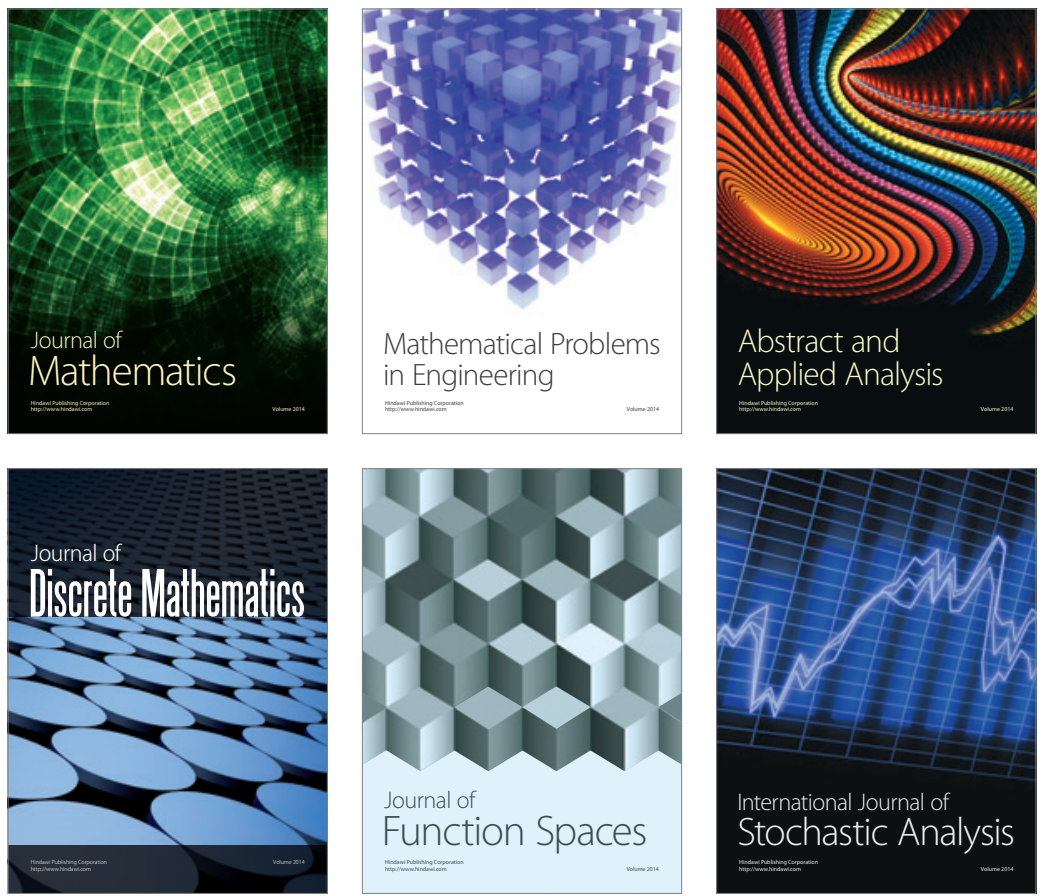

Journal of

Function Spaces

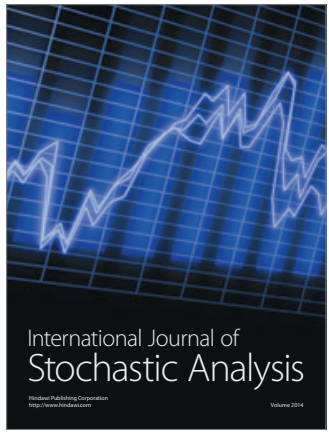

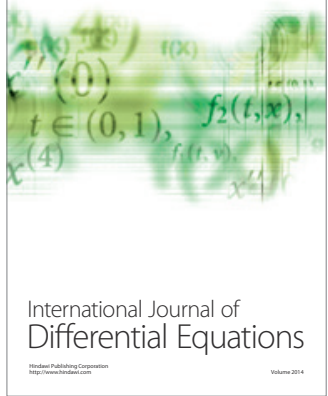
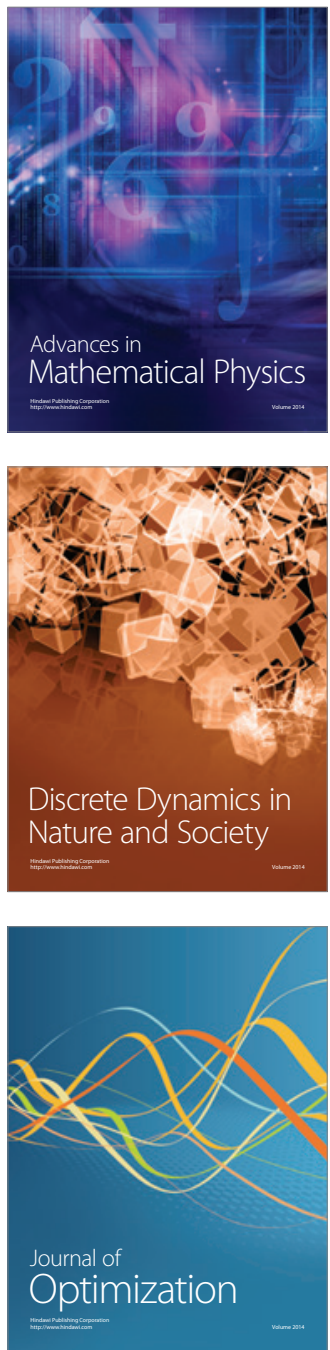